10-1-2008

\title{
Predicting length of treatment for neonatal abstinence syndrome in methadone-exposed neonates.
}

\author{
Neil S. Seligman \\ Thomas Jefferson University \\ Nicole Salva \\ Thomas Jefferson University \\ Edward J. Hayes \\ Thomas Jefferson University \\ Kevin C. Dysart \\ Thomas Jefferson University
}

Eollow this and additional works at: https://jdc.jefferson.edu/obgynfp

Edward C. Pequignot

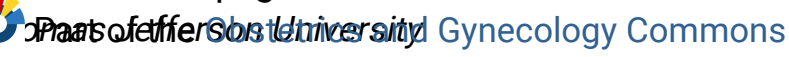

Let us know how access to this document benefits you

See next page for additional authors

\section{Recommended Citation}

Seligman, Neil S.; Salva, Nicole; Hayes, Edward J.; Dysart, Kevin C.; Pequignot, Edward C.; and

Baxter, Jason K., "Predicting length of treatment for neonatal abstinence syndrome in

methadone-exposed neonates." (2008). Department of Obstetrics and Gynecology Faculty

Papers. Paper 11.

https://jdc.jefferson.edu/obgynfp/11

This Article is brought to you for free and open access by the Jefferson Digital Commons. The Jefferson Digital Commons is a service of Thomas Jefferson University's Center for Teaching and Learning (CTL). The Commons is a showcase for Jefferson books and journals, peer-reviewed scholarly publications, unique historical collections from the University archives, and teaching tools. The Jefferson Digital Commons allows researchers and interested readers anywhere in the world to learn about and keep up to date with Jefferson scholarship. This article has been accepted for inclusion in Department of Obstetrics and Gynecology Faculty Papers by an authorized administrator of the Jefferson Digital Commons. For more information, please contact:

JeffersonDigitalCommons@jefferson.edu. 


\section{Authors}

Neil S. Seligman, Nicole Salva, Edward J. Hayes, Kevin C. Dysart, Edward C. Pequignot, and Jason K.

Baxter 


\title{
As submitted to:
}

\section{American journal of obstetrics and gynecology}

\author{
And later published as:
}

\section{"Predicting length of treatment for neonatal abstinence syndrome in methadone exposed neonates."}

\author{
Volume 199, Issue 4, October 2008, Pages 396.e1-396.e7
}

\section{DOI: 10.1016/j.ajog.2008.06.088}

Neil S SELIGMAN MD(1), Nicole SALVA(1), Edward J HAYES MD MSCP(1), Kevin C DYSART MD(1), Edward C PEQUIGNOT MS(2), Jason K BAXTER MD MSCP(1)

Philadelphia, Pennsylvania

Thomas Jefferson University, Department of Obstetrics \& Gynecology (1), Thomas Jefferson University, Department of Pharmacology and Experimental Therapeutics (2), Thomas Jefferson University/Nemours Foundation, Department of Neonatology (3)

Presented at the Society of Maternal-Fetal Medicine $28^{\text {th }}$ Annual Meeting in Dallas, Texas on Thursday, January 28 to February 2, 2008.

Please send correspondence and reprint requests to:

Neil Seligman

Business Address:

834 Chestnut Street; Suite 400

Philadelphia, PA 19107

Home Address:

705 Fulton Street

Philadelphia, PA 19147

eMail: neil.seligman@mail.tju.edu or n.seligman@ @otmail.com phone\#: (215) 756-4897

fax\#: (215) 955-5041

No financial support to declare. 
Abstract Word Count: 142

Total Word Count: 2,581

Condensation: Gestational age at delivery and maternal benzodiazepine use predict longer lengths of treatment for neonatal abstinence syndrome in neonates of mothers on methadone maintenance. 


\title{
Predicting length of treatment for neonatal abstinence syndrome in methadone exposed neonates.
}

\author{
Neil S SELIGMAN MD, Nicole SALVA, Edward J HAYES MD MSCP, Kevin C DYSART \\ MD, Edward C PEQUIGNOT MS, Jason K BAXTER MD MSCP
}

\begin{abstract}
Objectives: To identify maternal variables predicting length of treatment for neonatal abstinence syndrome (NAS).

Study Design: Retrospective cohort study of infants treated for NAS during 2000-2006 whose mothers were on methadone maintenance at delivery. Mixed effects linear regression was used to examine the interaction of maternal and neonatal variables with length of treatment.

Results: Of 204 neonates, born to methadone exposed mothers, average dose at delivery was 127 mg daily (25-340 mg) with median length of treatment 32 days (1-122 days). Trimester of initial exposure $(\mathrm{p}=0.33)$, methadone dose at delivery $(\mathrm{p}=0.198), \mathrm{BMI}(\mathrm{p}=0.31)$, antidepressant use $(\mathrm{p}=0.40)$, cigarette use $(\mathrm{p}=0.76)$, race $(\mathrm{p}=0.78)$ and maternal age $(\mathrm{p}=0.84)$ did not predict length of treatment. In the multivariate analysis gestational age at delivery and benzodiazepine use were significant predictors of length of treatment.

Conclusions: Later gestational age and concomitant benzodiazepine use were associated with longer treatment.
\end{abstract}

Key Words: antenatal methadone; neonatal withdrawal; drug abuse 


\section{Introduction}

Illicit drug use is prevalent among reproductive age women. A survey of combined data from 2005 and 2006 reported that $10 \%$ of women of childbearing age used illicit drugs (1). Of these women, $4 \%$ disclosed illicit drug use in the past month while pregnant (1). Intrauterine exposure to opiates may lead to neonatal withdrawal characterized by central nervous system irritability, gastrointestinal dysfunction, and autonomic signs (2). The constellation of findings is termed neonatal abstinence syndrome (NAS).

Management of opioid-dependence with methadone has been used since the 1960's to improve maternal and neonatal outcome (3). Methadone maintenance is associated with more prenatal care, improved fetal growth, and increased likelihood of discharge to parents' care (4). Despite its benefits, withdrawal from methadone is more severe than withdrawal from heroin, which translates into lengthier hospital stays causing a substantial burden on families (5). In large methadone treatment programs, treatment of NAS in otherwise healthy neonates in the neonatal intensive care unit is resource intensive and a substantial expense. At our institution, NAS occurs in $62-74 \%$ of neonates exposed to opiates in utero (6), and length of treatment for these neonates ranges from 7-49 days (7). These treatment statistics compare with results reported at other institutions.

Efforts to reduce the severity of withdrawal have largely focused on methadone administration and treatment of NAS. Initiating pharmacologic treatment for NAS decreases the duration of symptoms (2) but does not subjugate the necessity to decrease the severity of withdrawal through antenatal interventions. The majority of literature on methadone administration is concentrated on dosage and the findings regarding an association between maternal methadone dose and the severity of neonatal withdrawal conflict $(6,8,9,10,11,12,13$, 
14, 15). The optimal dose remains a topic of clinical debate. Methadone dose is only one aspect of treating opiate addiction. The role that other aspects of maternal treatment play in mitigating or potentiating the severity of neonatal withdrawal is largely unstudied. The purpose of this study was to determine which maternal variables predict the length of treatment for NAS in methadone exposed neonates.

\section{Material and Methods}

Institutional review board approval was obtained to conduct a retrospective chart review. The hospital medical records database was queried using the International Classification of Diseases codes for antepartum drug dependence (648.33), maternal drug dependence with delivery (648.31), and opioid dependence continuous use (304.01). The inpatient medical records of methadone maintained women who delivered between January $1^{\text {st }}, 2000$ and June $30^{\text {th }}, 2006$ and had urine drug screen (UDS-9) positive for methadone within the two weeks preceding the delivery date were reviewed. The "drugs of abuse" (DAU) screen does not test for methadone. Records were also reviewed for women whose DAU at delivery was negative for opiates if there was documentation of methadone use in the patient's medical record. Neonatal charts were reviewed and only neonates diagnosed with NAS and their mothers were included in the study. Additional information was obtained from outpatient obstetrical clinic records, the Childrens Rehabilitation Hospital records, and from General Electric Medical Systems Quantitative Sentinel. Patients were excluded if the length of neonatal treatment could not be determined or if the neonate was enrolled in a coinciding NAS treatment study with an experimental drug. Stillbirths and deliveries at less than 23 weeks were also excluded. 
In Philadelphia, Pennsylvania, only Thomas Jefferson University Hospital offers a comprehensive program for methadone stabilization of opiate addicted pregnant women which has been described previously (6). The stabilization protocol was an initial methadone dose of $20-30 \mathrm{mg}$ orally followed by $5-10 \mathrm{mg}$ every 6 hours as needed for withdrawal symptoms. On each consecutive day, the new dose was the total dose of methadone administered in the prior 24 hours. Patients were discharged when they had been stable without additional doses of methadone for at least 12-18 hours after the last dose. Pregnant women that were not admitted for methadone stabilization were assumed to be on methadone at the time of conception for the purpose of determining the trimester of initial exposure to methadone and the length of exposure to methadone.

All of the neonates were delivered at Thomas Jefferson University Hospital. The neonates were transferred to the newborn nursery in the absence of other co-morbidities. An objective score was assigned every eight hours for the first 72 hours of life according to the Finnegan scoring system (16). An average of the three scores greater than 24 was criteria for treatment of NAS. Standard of care treatment at Thomas Jefferson University Hospital consists of an initial dose of morphine $0.4 \mathrm{mg} / \mathrm{kg} / \mathrm{day}$ (in the form of neonatal opium solution) in 6 divided doses with dose escalation of 10\%/day for Finnegan scale scores greater than 24 total on either 2 or 3 measures. Maximum dosage was $2 \mathrm{mg} / \mathrm{kg} / \mathrm{day}$, after which adjunctive treatment with phenobarbital was initiated. Infants were weaned from neonatal opium solution (NOS) once they demonstrated control of their NAS as measured by the Finnegan scale for 48 hours. Daily dose was weaned by $10 \%$ every 48 hours as the infant tolerated. If an infant required rescue therapy the equivalent of one extra dose of NOS was given. Infants are discontinued from treatment when they demonstrated no signs of abstinence as measured on the Finnegan scale and 
reach a dose of $0.15 \mathrm{mg} / \mathrm{kg} / \mathrm{day}$. Length of treatment was defined as the duration of pharmacologic treatment for NAS.

The following variables were compared to length of treatment for NAS: length of exposure to methadone, trimester of initial exposure, methadone dose at delivery, maternal body mass index (BMI), antidepressant use, benzodiazepine use, tobacco use, alcohol use, gestational age at delivery, race, and maternal age. Methadone dose at delivery was defined as the methadone dose within the 24 hours prior to delivery. Maternal BMI was calculated using weight at delivery. First urine drug screen (UDS) was defined as the first available UDS more than two weeks prior to delivery. Last UDS was defined as the composite results of all UDS within 2 weeks of delivery. Benzodiazepine use was defined as last UDS positive for benzodiazepines or a history of prescription benzodiazepine use during the index pregnancy.

Length of treatment was transformed by taking square roots to normalize residuals. The association between transformed length of treatment and various clinical and demographic factors was analyzed using a mixed effects linear regression. Variables significant at the univariate level $(\mathrm{p}<0.20)$ were entered into a multivariate mixed effects model as fixed effects. A random intercept term was included to account for correlation among infants born to the same mother. The number of neonates included in the multivariate analysis was determined by the number of non-missing values for length of treatment and the independent variables. Model adjusted least-squares means (using observed marginal sample sizes) were calculated from estimates from the multivariate model and squared to obtain values on the original scale.

\section{Results}


Maternal and Neonatal Demographics. Our cohort consisted of 185 methadone maintained women and 204 neonates including two sets of twins. Thirteen women delivered twice and two women delivered three times. The median length of NAS treatment was 32 days (range 1-122). For unknown reasons, the average length of treatment increased between 20002003, and then plateaued (Figure 1). Maternal demographics are shown in Table 1. With regard to the first delivery during the study period, $16 \%$ of women were primiparous and $84 \%$ were multiparous. Most women (72.1\%) were stabilized on methadone after conception. The overall average maternal methadone dose was $127 \mathrm{mg}$ daily. The delivery dose of methadone was $>150$ mg daily in $31.4 \%$ of women and $>200 \mathrm{mg}$ daily in $11.8 \%$ of women.

Demographics for the 204 neonates grouped by gestational age at birth are presented in Table 2. Overall, the rate of preterm birth $<37$ weeks was $36.3 \%$. As expected, birth weight and head circumference were significantly different among gestational age groups and increased with later gestational age at birth. No other differences were noted by gestational age groups at birth.

Univariate and Multivariate Analysis of Variables. Table 3 shows the univariate analysis of maternal variables for all neonates. There was a statistically significant relationship between length of neonatal treatment for NAS and both concomitant benzodiazepine use $(\mathrm{p}=0.002)$ and gestational age at delivery $(\mathrm{p}<0.001)$. After controlling for the possible interaction of significant variables $(\mathrm{p}<0.2)$ including length of exposure, time of initial exposure, methadone dose at delivery, alcohol use and gestational age at delivery, adjusted mean length of treatment was 14.4 days longer in women who used benzodiazepines (Table 4). As shown in Table 5, statistical significance remained in a subanalysis excluding preterm births less than 33 weeks gestational age $(\mathrm{p}<0.001)$. 
Length of treatment also increased with later gestational age at birth in the univariate (Table 3) and multivariate analysis (Table 4). Adjusted mean length of treatment increased from 11.9 days in neonates born between 23-32 6/7 weeks gestational age $(n=11)$ to 26.2 days in neonates born between and 33-36 6/7 weeks ( $\mathrm{n}=62)$ gestational age to 38.1 days in neonates born at term $(\mathrm{n}=128)$. All pairwise group differences were significant (Bonferroni adjusted $\mathrm{p}<0.05)$.

Women whose last UDS was positive for methadone and did not use any other illicit drugs, except marijuana, were evaluated separately (Table 5). In these women there was no difference in length of treatment between infants born between 23-32 6/7 weeks and 33-36 6/7 weeks gestational age but there were only five neonates born at less than 33 weeks gestational age. Length of treatment was significantly longer in infants born 37-42 weeks gestational age than in infants born in either of the other two gestational age groups $(\mathrm{p}<0.001)$. A similar pattern was seen in a subset analysis excluding births less than 33 weeks $(\mathrm{p}<0.001)$ (Table 5).

Initiation of methadone maintenance more than 10 weeks prior to delivery was associated with an 8.8 day increase in length of treatment $(\mathrm{p}=0.028)$ in the subset of neonates born after 32 weeks gestational age but not in the other two groups (Table 5). In this same subgroup, length of treatment was significantly different between delivery doses of 101-150 $\mathrm{mg}$ and 151-200 $\mathrm{mg}$. In these two dose groups length of treatment decreased from an adjusted mean of 39.0 days to 25.7 days. No other variables were found to be significant.

\section{Comment}

Benzodiazepine use and gestational age at birth were the two maternal variables identified by our study that predict the length of treatment for NAS. Neonates exposed to benzodiazepines and those born at term had a significantly longer length of treatment when 
compared to unexposed neonates or to those born at $<37$ weeks gestational age. Our results also demonstrate that with regard to length of treatment, there is no significant relationship to maternal methadone dose prior to delivery. Length of neonatal treatment could not be predicted by any of the other variables studied.

Strengths of our study are that our cohort's mean and maximum doses of methadone are amongst the highest reported in pregnancy in the English literature. This is also one of the largest cohorts of neonates objectively diagnosed with NAS that received standardized treatment. Our systematic evaluation considered the relationship between length of treatment of NAS and a broad range of antenatal maternal variables in three categories: a) methadone maintenance (e.g. dose), b) substance abuse (e.g. alcohol use), c) and variables unrelated either of the other two categories (e.g. race). Limitations of this approach are the facts that we did not consider the effect of neonatal factors such as breast feeding or different pharmacologic treatments for NAS, and the lack of validation of the scoring system in premature infants.

The association of benzodiazepine use with longer length of treatment confirms earlier studies in smaller samples at our $(6)$ or other $(17,18)$ centers. Symptoms of benzodiazepine withdrawal confound neonatal abstinence score during treatment because of delayed onset as late as day 12 to day $21(2,18)$ and may be prolonged $(19)$. Opiates used in the treatment of NAS have no effect on withdrawal from non-opiates. Alternative to benzodiazepines, such as antidepressants, for treatment of anxiety in methadone maintained mothers may be considered in light of these findings. Antidepressant use, most of which were selective serotonin reuptake inhibitors, was not associated with longer length of treatment in our study but the relationship deserves further research.

The other major finding in our study was the direct association between later gestational 
age at birth and longer length of neonatal treatment for NAS. Doberczak et al. first demonstrated more severe abstinence symptoms in term versus preterm neonates (9). Consequently, Dysart et al, found that in our center, severity of symptoms translates to lengthier treatment (7). One simple explanation is that term infants have greater intrauterine methadone exposure (9). Neither measure of total exposure in our study, which included length of exposure and trimester of initial exposure, or those in other studies $(13,14)$ were significant. The association between gestational age and length of treatment is also explained by several biologically plausible mechanisms. One theory is that incomplete dendritic developmental may alter clinical expression of NAS (9). Another explanation is slower weaning due to delayed and hepatic (7) and placental (20) metabolism of methadone in premature neonates. A final explanation is increased placental transfer of methadone to the neonatal circulation at term (21). The effect intravenous medications have on length of treatment when oral feedings are held should be considered.

The appropriate methadone dose is controversial. Our results demonstrate that with regard to length of treatment, there is no relationship to maternal methadone dose at delivery. Prior studies on high dose maternal methadone showed no difference in the incidence of treatment of NAS between high-dose ( $>80$ or $>100 \mathrm{mg} / \mathrm{d}$ ) and low dose $(<80$ or $<100 \mathrm{mg} / \mathrm{d})$ maternal methadone groups, and less illicit drug use in the high-dose group $(6,22)$. Women who resort to heroin while on methadone negate the positive effect of methadone on the outcomes of their infants (23). The high doses in our cohort are partially a reflection of the amount of heroin use in our cohort and relative differences in the potency of different varieties of heroin. The best explanation for why methadone dose and length of treatment are unrelated is because methadone metabolism is enhanced to variable degrees in the pregnancy (15). In fact methadone trough levels do not correlate well with maternal dosage (24), so that maternal methadone dose should 
be decided based on maternal symptoms, with no predetermined maximum. Positive results may also be achieved in women who undergo supervised withdrawal to doses less than $20 \mathrm{mg}$ daily $(8,10)$. Split daily dosing may be another alternative to maintain plasma methadone levels at lower overall doses $(25,26)$.

In conclusion, the main findings of our study were that benzodiazepine use and later gestational age at birth increase length of neonatal treatment for NAS. This study provides practical guidance for the clinician treating opiate-addicted pregnant women. Clinicians should not be hesitant to use higher doses of methadone to ameliorate withdrawal or in the asymptomatic woman. Consideration should be given to avoiding benzodiazepines in methadone maintained mothers when a suitable alternative is available. It is expected that some women will continue to use benzodiazepines illicitly and the optimal treatment for these neonates with concomitant opiate and benzodiazepine withdrawal is unknown. 


\section{Acknowledgements}

We would like to acknowledge the hard work of Marie O'Neill, MD and Jennifer Kern BS who meticulously collected data. We also appreciate the statistical support of Ben Leiby, PhD. A final thanks to Vincenzo Berghella, MD whose expertise on methadone and research in general was a valuable aid during the editing of our manuscript. 


\section{References}

1. Substance Abuse and Mental Health Services Administration. (2007). Results from the 2006 National Survey on Drug Use and Health: National Findings (Office of Applied Studies, NSDUH Series H-32, DHHS Publication No. SMA 07-4293). Rockville, MD.

2. Neonatal Drug Withdrawal. American Academy of Pediatrics Committee on Drugs. Pediatrics. 1998 Jun;101(6):1079-88

3. Kaltenbach K, Berghella V, Finnegan L. Opioid dependence during pregnancy: effects and management. Obstet Gynecol Clin North Am. 1998; 25(1): 139-151

4. Fajemirokun-Odudeyi O, Sinha C, Tutty S, Pairaudeau P, Armstrong D, Phillips T, Lindow SW. Pregnancy outcome in women who use opiates. European Journal of Obstetrics and Gynecology and Reproductive Biology. 2006;126: 170-175.

5. Johnson K, Greenough A, Gerada C. Maternal drug use and length of neonatal unit stay. Addiction. 2003; 98:785-789

6. Berghella V, Lim PJ, Hill MK, Cherpes J, Chennat J, Kaltenbach K. Maternal methadone dose and neonatal withdrawal. Am J Obstet Gynecol. 2003;189(2): 312-317

7. Dysart K, Hsieh HC, Kaltenbach K, Greenspan JS. Sequela of preterm versus term infants born to mothers on a methadone maintenance program: differential course of neonatal abstinence syndrome. J Perinat Med. 2007; 35(4): 344-346

8. Dashe JS, Sheffield JS, Olscher DA, Todd SJ, Jackson GL, Wendel GD. Relationship between maternal methadone dosage and neonatal withdrawal. Obstet Gynecol. 2002; 100(6): 1244-1249.

9. Doberczak TM, Kandall SR, Wilets I. Neonatal opiate abstinence syndrome in term and preterm infants. J Pediatr. 1991 Jun;118(6):933-7. 
10. Harper RG, Solish G, Feingold E, Gersten-Woolf FB, Sokal BM. Maternal ingested methadone, body fluid methadone, and the neonatal withdrawal syndrome. Am J Obstet Gynecol. 1977; 129:417-424.

11. Kaltenbach K. Methadone maintenance of greater than $80 \mathrm{mg}$ during pregnancy. NIDA Res Monogr. 1997;174:128.

12. McCarthy JJ, Leamon MH, Parr MS, Anania B. High-dose methadone maintenance in pregnancy: maternal and neonatal outcomes. Am J Obstet Gynecol. 2005; 193: 606-610.

13. Madden JD, Chappel JN, Zuspan F, Gumpel J, Mejia A, Davis R. Observation and treatment of neonatal narcotic withdrawal. Am. J Obstet Gynecol. 1997; 127: 199-201.

14. Ostrea EM, Chavez CJ, Strauss ME. A study of factors that influence the severity of neonatal narcotic withdrawal. J Pediatr 1976; 88(4):642-645.

15. Rosen TS, Pippenger CE. Pharmacologic observations on the neonatal withdrawal syndrome. J Pediatr. 1977; 88(6):1044-1048.

16. Finnegan LP, Connaughton JF, Jr,, Kron RE, Emich JP. Neonatal abstinence syndrome: assessment and management. Addict Dis 1975; 2(1-2):141-58

17. Abdel-Latif ME, Pinner J, Clews S, Cooke F, Lui K, Oei J. Effects of breast milk on the severity and outcome of neonatal abstinence syndrome among infants of drug-dependent mothers. Pediatrics. 2006 Jun;117(6):e1163-9.

18. Sutton LR, Hinderliter SA. Diazepam abuse in pregnant women on methadone maintenance. Implications for the neonate. Clin Pediatr (Phila). 1990 Feb;29(2):108-11.

19. Oei J, Lui K. Management of the newborn infant affected by maternal opiates and other drugs of dependency. J Paediatr Child Health. 2007 Jan-Feb;43(1-2):9-18. 
20. Hieronymus TL, Nanovskaya TN, Deshmukh SV, Vargas R, Hankins GDV, Ahmed MS. Methadone metabolism by Early Gestational Age Placentas. Am J Perinatol 2006; 23(5):287-294 21. Nanovskaya TN, Nekhayeva IA, Hankins GDV, Ahmed MS. Transfer of methadone across the dually perfused preterm human placental lobule. Am J Obstet gynecol. 2008; 198:126e1$126 \mathrm{e} 4$

22. McCarthy JJ, Leamon MH, Parr MS, Anania B. High-dose methadone maintenance in pregnancy: maternal and neonatal outcomes. Am J Obstet Gynecol. 2005 Sep;193(3 Pt 1): 60610.

23. Hulse GK, Milne E, English DR, Holman CDJ. The relationship between maternal use of heroin and methadone and infant birth weight. Addiction 1997; 92(11): 1571-1579

24. Drozdick JD, Berghella V, Hill MK, Kaltenbach K. Methadone trough levels in pregnancy. Am J Obstet Gynecol 2002; 187(5):1184-1188.

25. DePetrillo PB, Rice JM. Methadone dosing and pregnancy: impact on program. The Int $\mathbf{J}$ Addicti. 1995; 30(2):207-17.

26. Swift RM, Dudley M, DePetrillo P, Camara P, Griffiths W. Altered methadone pharmacokinetics in pregnancy. J Subst Abuse 1989; 1(4): 453-60. 
Figure 1. The trend in length of treatment over time for all neonates treated for NAS during the study period. 